\title{
Phenotypic and Genetic Variation
}

\section{in the Susceptibility of Haemophilus influenzae Type b}

\section{to Antibodies to Somatic Antigens}

\author{
Porter Anderson, Alan Flesher, Stephen Shaw, A. Lynn Harding, and \\ David H. SMITH, Department of Pediatrics, University of Rochester Medical \\ Center, Rochester, New York 14642
}

\begin{abstract}
A B S T R A C T Haemophilus influenzae type b (H.i.b) has been investigated with respect to phenotypic and genetic variations resulting in differential susceptibility to bactericidal antibody. Previous studies had shown that after growth in infected rats or in dialysate of rat serum, H.i.b strain Eag became more resistant to the bactericidal activity of antisomatic antibody. We now report that a similar phenotypic shift occurs when strain Eag is incubated with dialysate of human serum, that the increased resistance is to antibodies against determinants in the lipopolysaccharide not for the somatic antigens generally, and that most strains of H.i.b undergo the shift.
\end{abstract}

To assess genetic differences in exposed antigens, a panel of 13 H.i.b isolates from cerebrospinal fluid were analyzed with cross-adsorbed antisera. Seven different patterns were found that could be accounted for through the variable expression of six antigens. These ranged from infrequent (found on 1:13 strains) to common (10:13 strains). At least four were somatic rather than capsular determinants; the most common (antigen 1) was contained in lipopolysaccharide.

The epidemiologic relevance of the genetic variations was explored using pairs of isolates from two children who had had two documented infections with H.i.b. In both cases the isolates varied in somatic antigen expression. The strains from one patient differed in the expression of antigen 1 . The isolates from the other were indistinguishable in sub-typing for the six classified antigens, but differed in the expression of an additional antigen identified by use of the patient's serum.

The present address of Dr. Flesher and Ms. Harding is Harvard Medical School, Boston, Mass. Dr. Shaw's present address is Metabolism Branch, National Cancer Institute, Bethesda, Md.

Received for publication 5 November 1979 and in revised form 20 December 1979.

\section{INTRODUCTION}

The capsular polysaccharide $(P R P)^{1}$ is a principal virulence determinant in invasive infections by Haemophilus influenzae type b (H.i.b) $(1,2)$. Anti-PRP antibodies proved therapeutic when passively administered for H.i.b meningitis (2), and PRP-vaccinated children 1.5-6 yr old appeared to be protected in a recent field trial (3).

Potentially protective antibodies may be directed also against somatic antigens (here defined as surface components other than PRP). Because the finding that complement-dependent serum bactericidal (BC) antibody in healthy human subjects has an age distribution inverse to the incidence of H.i.b meningitis $(4,1)$, serum BC activity has been viewed generally although not universally (5) as an indicator of immunity. BC activity was reported in human sera in which antiPRP antibody was not detected $(6,7)$ or -in light of more sensitive assays - sera in which anti-PRP titers appeared insufficient for BC activity $(8,9)$. BC $(7,10)$ and opsonic (7) activity remained in certain sera despite adsorption with purified PRP. In experimental animals antisomatic antibodies can facilitate bloodstream clearance (11) and protect against lethal challenge $(12,13)$.

The relevance of antisomatic antibodies for host resistance was somewhat clouded, however, by the finding that H.i.b strain Eag grown in conventional broth medium is more susceptible to the BC activity of rat antisomatic antibodies than the same strain obtained from experimentally infected rats. This differential could be mimicked by brief exposure of broth-

\footnotetext{
${ }^{1}$ Abbreviations used in this paper: $\mathrm{BC}$, bactericidal; CFU, colony-forming units; H.i.b, Haemophilus influenzae type b; HSD, human serum dialysate; LPS, lipopolysaccharide; PCMA, phosphate-buffered saline containing $\mathrm{Ca}^{++}$, $\mathrm{Mg}^{++}$, and albumin; PRP, capsular polysaccharide of $\mathrm{Hae}-$ mophilus influenzae b.
} 
grown bacteria to component(s) of rat serum of $<1,000 \mathrm{~mol}$ wt (14). In the present report such a phenotypic shift is shown to occur also in response to dialyzable components of human serum and is further described in respect to antigen specificity and strain distribution.

The somatic antigens of H.i.b are not well described biochemically. As expected of a gram-negative bacterium, the outer membrane of $H$. influenzae Rd (rough variant of type d) was found to contain lipopolysaccharide (LPS) and a number of proteins, but the antigenicity of these components was not studied (15). Phenol extraction of H.i.b yielded a toxic fraction resembling LPS (16). Rabbits immunized with H.i.b produced antibodies to LPS as well as to PRP (17); whether the anti-LPS antibodies were bactericidal to intact H.i.b was not studied. LPS from H.i.b strain Eag recently has been isolated and partially characterized biochemically (18). This preparation has been used in the present study to examine the extent to which antisomatic bactericidal antibodies can be LPSdirected.

Practically all invasive $H$. influenzae infections are caused by serotype b. For approaching epidemiologic questions a method of subtyping H.i.b isolates would be useful. ${ }^{2}$ The differential susceptibility of strains to $\mathrm{BC}$ activity of PRP-adsorbed sera $(7,10)$ suggested heterogeneity among H.i.b in somatic antigens exposed to antibody. Bactericidal analysis with cross-adsorbed antiserum reagents proved useful for subgrouping of Neisseria meningitidis group C strains (20), and we here describe the application of this technique to subtyping of H.i.b isolates. The epidemiologic utility of the classification was examined with isolates from two children who developed a second H.i.b systemic infection within a few months of recovery from a first such infection.

\section{METHODS}

Bacteria. The origin of H.i.b strains is given in Tables II and IV; all but one were isolated from cerebrospinal fluid. The preservation of strains and the initiation and quantitation of liquid cultures have been described (7). Bacteria were grown at $37^{\circ} \mathrm{C}$ in shaken, baffled flasks to a density of $10^{9}$ colony-forming units $(\mathrm{CFU}) / \mathrm{ml}$ in BHI-BD broth, which is brain heart infusion (Difco Laboratories, Detroit, Mich.) supplemented with horse blood lysate and NAD (7); they were chilled to $0^{\circ} \mathrm{C}$ and used within $1 \mathrm{~h}$ after chilling. For washed bacteria, the culture was centrifuged $10 \mathrm{~min}$ at 8,000 $g$, and the bacterial pellet was suspended to original volume in the washing fluid and recentrifuged.

Sera and serum reagents. Human anti-PRP serum was obtained $2 \mathrm{wk}$ after subcutaneous injection of an adult volun-

${ }^{2}$ A nonserologic "biotyping" scheme for the genus Haemophilus has been devised by Kilian (19); however, nearly all invasive H.i.b isolates fall within the same biotype. teer with $30 \mu \mathrm{g}$ of the purified antigen from strain Eag (21) in saline. Rabbit antisera to LPS of strain Eag (LPS Eag $\left._{\text {g }}\right)$ (18) were produced by three intravenous injections of $0.5 \mu \mathrm{g}$ at weekly intervals followed by 12 injections of $100 \mu \mathrm{g}$ given twice weekly. Rabbit antisera to whole H.i.b were raised by intravenous injection of live bacteria washed in phosphate-buffered saline (7); an initial dose of $10^{6} \mathrm{CFU}$ was followed by three doses of $10^{8}$ at weekly intervals. For adsorption of serum with H.i.b the bacteria were washed in phosphate-buffered saline containing $0.15 \mathrm{mM} \mathrm{CaCl}$, $0.5 \mathrm{mM} \mathrm{MgCl}$, and $0.1 \%$ bovine serum albumin (PCMA). The washed bacterial pellet was suspended in chilled serum at $3 \times 10^{10} \mathrm{CFU} / \mathrm{ml}$; after $1 \mathrm{~h}$ at $0^{\circ} \mathrm{C}$ the suspension was centrifuged and the supernate transferred to a fresh bacterial pellet; after $1 \mathrm{~h}$ the suspension was centrifuged and the supernate further clarified by passage through a $0.22-\mu \mathrm{m}$ filter (Millex, Millipore Corp., Bedford, Mass.). The adsorbed reagent was considered satisfactory if the BC titer against the adsorbing strain was $<2$; otherwise the adsorption was repeated. The term adsorption is also applied to fluid-phase inhibition with excess PRP or LPS Eag; this was done by adding the inhibitor in a negligible volume of water to achieve $40 \mu \mathrm{g} / \mathrm{ml}$ and incubating $15 \mathrm{~min}$ at $37^{\circ} \mathrm{C}$ followed by $2 \mathrm{~h}$ at $0^{\circ} \mathrm{C}$. Completeness of inhibition was established for PRP by radioantigen binding (22) and for LPS by an enzyme-linked immunoadsorbent assay (23). As a control against nonspecific inhibition of $\mathrm{BC}$ activity by soluble components eluted from the bacteria, by the added PRP or LPS, or by immune complexes, the adsorbed reagents were tested in the $\mathrm{BC}$ assay against antibody-sensitized H.i.b, prepared by incubation of the bacteria $30 \mathrm{~min}$ at $0^{\circ} \mathrm{C}$ with heat-inactivated human anti-PRP serum at $1: 160$ dilution. None of the reagents employed inhibited killing of the sensitized H.i.b by complement.

The complement source for the BC assay was serum from a calf denied colostrum (kindly provided by J. B. Robbins, Bureau of Biologics, U. S. Food and Drug Administration).

Dialysates of normal human sera were prepared by aseptic dialysis from a sac of cellulose membrane, 12,000-mol wt exclusion, into equal volumes of PCMA at $4^{\circ} \mathrm{C}$ overnight; the dialysates were stored at $-70^{\circ} \mathrm{C}$.

$B C$ assay. Bacteria were prepared for the assay by dilution to $10^{5} \mathrm{CFU} / \mathrm{ml}$ in PCMA at $0^{\circ} \mathrm{C}$. For preincubation with human serum dialysate, equal volumes of this suspension and the dialysate were incubated $30 \mathrm{~min}$ at $37^{\circ} \mathrm{C}$ and chilled to $0^{\circ} \mathrm{C}$; the viable count approximately doubled, compensating for the 1:1 dilution. Incubation of the bacterial suspension $30 \mathrm{~min}$ at $37^{\circ} \mathrm{C}$ in PCMA alone had no effect on susceptibility. A mixture consisting of one part bacterial suspension, two parts complement source and five parts PCMA was made at $0^{\circ} \mathrm{C}$, and $25 \mu \mathrm{l}$ was added to $25 \mu \mathrm{l}$ of (serial dilutions in PCMA of) the serum being tested for antibody. After 30 min of incubation at $37^{\circ}$ the viable count was compared with an antibody-free control incubation, and the reciprocal of the greatest dilution giving $>50 \%$ reduction was recorded as the $\mathrm{BC}$ titer.

Patients. Baby girl Tur was admitted to Children's Medical Center, Boston with H.i.b meningitis at age $10 \mathrm{mo}$, successfully treated with intravenous ampicillin, and discharged free of symptoms after $14 \mathrm{~d}$. At age 16 mo she was again admitted with H.i.b meningitis. Baby girl Sil was admitted with H.i.b sepsis and meningitis at age $8 \mathrm{mo}$, successfully treated with ampicillin, and discharged after $10 \mathrm{~d}$. 31 d later she was admitted for H.i.b sepsis without meningitis; upon admission H.i.b was cultured from her nasopharynx as well as her blood. 


\section{RESULTS}

Phenotypic variation in strain Eag. The effect of incubation of broth-grown H.i.b strain Eag for $30 \mathrm{~min}$ at $37^{\circ} \mathrm{C}$ with human serum dialysate upon susceptibility to several antiserum reagents is given in Table $\mathrm{I}$. The BC titer of normal human serum T159 adsorbed with PRP was reduced from 16 to 2 (line 1); this serum was chosen for illustration because of its relatively high antisomatic antibody content, but a differential was seen with many other normal sera. In contrast, the titer of human serum high in anti-PRP was the same irrespective of the exposure of H.i.b to dialysate (line 2); this serum was a post-PRP-vaccination sample from an individual whose $\mathrm{BC}$ titer was $<2$ before vaccination, and therefore the $\mathrm{BC}$ antibody is almost entirely anti-PRP. Thus a phenotypic shift of H.i.b Eag revealed with serum ultrafiltrate and antisomatic antibodies of the rat (14) is reproduced with human serum components. A shift was found with rabbit R217 antiserum to purified LPS of H.i.b strain Eag (line 3); a similar differential was seen with the sera of two additional rabbits immunized with this LPS (not illustrated). In rabbit antisera to whole H.i.b (illustrated with R15) BC activity remained after adsorption with both PRP and LPS, but a differential due to serum dialysate was not seen (line 4). Thus the phenotypic shift applies not to antisomatic antibodies generally but appears to be a differential susceptibility to antibodies against determinant(s) in LPS. A shift was produced by dialysate of three of three tested samples of normal human serum.

Genetic variation. For examination of the strain distribution of antibody-accessible somatic antigens among H.i.b, a panel of 12 cerebrospinal fluid isolates in addition to Eag was analyzed by preparing rabbit antisera to the exponential phase bacteria, adsorbing with one or more heterologous strains, and testing for residual activity. So as to better reveal differences in LPS antigens, bacteria not treated with dialysate

TABLE I

Effect of Incubation with Human Serum Dialysate (HSD) on the Susceptibility of Strain Eag to Antisera of Various Specificities

\begin{tabular}{lcrr}
\hline & & \multicolumn{2}{c}{$\begin{array}{c}\text { BC titer against } \\
\text { bacteria prepared }\end{array}$} \\
\cline { 3 - 5 } \multicolumn{1}{c}{ Serum } & Adsorbent & -HSD & + HSD \\
\hline Normal human T159 & PRP & 16 & 2 \\
Human 78-84 anti-PRP & - & 640 & 640 \\
Rabbit R217 anti-LPS & - & 640 & 40 \\
Rabbit R15 anti-H.i.b Eag & PRP + LPS & 64 & 64 \\
\hline
\end{tabular}

were used for immunization, adsorption, and testing. In all, antisera were made against 11 strains (one to three rabbits per strain), and 53 adsorbed reagent antisera were eventually tested. Equivalently prepared reagents from different rabbits generally gave the same result; where results differed, the broadest activity was taken as the most meaningful. Table II summarizes the activity of reagents demonstrating the seven different patterns of susceptibility noted; the many redundant results are not included. The reagents varied in breadth of activity from anti-Eag/Mad (antiserum vs. Eag adsorbed on Mad), which killed 10 of 13 strains, to anti-Mad/H305, which killed only strain Mad itself. Internally consistent reciprocal results were found (not illustrated). For example, just as reagent anti6510/H252 killed strain C60 (Table II), anti-C60/H252 killed 6510. Similarly, any one of strains H252, H234, or C51 could completely absorb activity elicited by the other two (not shown). Thus a system of six differentially expressed antigens could be assigned within the panel (Table II, last line and last column).

The relationship between these antigens and LPS was explored. R217 anti-LPS Eag $_{\text {antiserum was tested }}$ against prototype strains of each antigen makeup and found to have a broad activity similar to the reagent for antigen 1 (anti-Eag/Mad). All strains expressing antigen 1 were susceptible; only strains H305 (antigen 5) and Mad (antigens 5 and 6) were insusceptible (Table III). Adsorption with LPS $_{\text {Eag }}$ completely removed the activity of reagent anti-Eag/Mad but not of reagents specific for the other antigens (not illustrated). One strain not expressing antigen 1 (H123) was suscep-

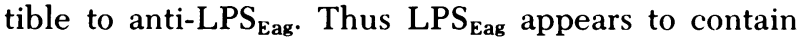
antigen 1 plus additional determinant(s) not classified, but not to contain antigens 2 through 6 .

Phenotypic variation in other strains. All strains susceptible to anti-LPS $S_{\text {Eag }}$ underwent an increase in resistance to this antiserum upon incubation with serum dialysate (Table III). A shift likewise was seen in resistance to the anti-Eag/Mad reagent but not to the other reagents of Table II (not illustrated).

Subtyping of isolates in recurrent infection. The six reagent antisera were applied to pairs of isolates from children who had had two systemic H.i.b infections (Table IV). Isolate 1 from patient Tur lacked susceptibility to all six reagents; her isolate 2 , however, was killed with the reagent for antigen 1 . This difference was also appreciated in their susceptibility to antiLPS $_{\text {Eag }}$ (titers of $<40$ and $>320$, respectively). Both isolates from patient $\mathrm{Sil}$ were susceptible to the antigen 1 reagent, were susceptible to anti-LPS ${ }_{\text {Eas }}$ at equal titers, and exhibited the phenotypic shift (not illustrated) with either reagent. Discrimination was sought further with reagents consisting of the patients' own 
TABLE II

Subtyping with Cross-Adsorbed Antisera of H.i.b Isolates from Cerebrospinal Fluid

\begin{tabular}{lllllllll}
\hline & & \multicolumn{7}{c}{ Susceptibility to antiserum reagent* } \\
\cline { 3 - 9 } Strain & $\begin{array}{l}\text { Place of } \\
\text { isolation }\end{array}$ & $\frac{\text { Eagt }}{\text { Mad }}$ & $\frac{\text { Rab }}{\text { Eag }}$ & $\frac{\text { H252 }}{\text { Eag + Rab }}$ & $\frac{6510}{\text { H252 }}$ & $\frac{\text { H305 }}{\text { Eag }}$ & $\frac{\text { Mad }}{\text { H305 }}$ & $\begin{array}{c}\text { Antigens } \\
\text { inferred } \\
\text { in strain }\end{array}$ \\
\hline Eag & Mass. & + & - & - & - & - & - & 1 \\
H292 & Ala. & + & - & - & - & - & - & 1 \\
H113 & Ala. & \pm & - & - & - & - & - & 1 \\
C58 & Mass. & \pm & - & - & - & - & - & 1 \\
6510 & Pa. & + & - & - & + & - & - & 1,4 \\
C60 & Mass. & + & - & - & + & - & - & 1,4 \\
H252 & Ala. & + & + & + & - & - & - & $1,2,3$ \\
H234 & Ala. & \pm & + & + & - & - & - & $1,2,3$ \\
C51 & Mass. & \pm & + & + & - & - & - & $1,2,3$ \\
Rab & N. Y. & \pm & + & - & - & - & - & 1,2 \\
H123 & Ala. & - & + & - & - & - & - & 2 \\
H305 & Ala. & - & - & - & - & + & - & 5 \\
Mad & Mass. & - & - & - & - & + & + & 5,6 \\
\hline
\end{tabular}

Antigen defined

$\begin{array}{lllllll}\text { by reagent } & 1 & 2 & 3 & 4 & 5 & 6\end{array}$

* Susceptibility of + is defined as a titer $>16$-fold, and \pm as 4- or 8-fold that of the respective preimmunization serum, similarly adsorbed.

† Antiserum against strain Eag adsorbed with strain Mad, etc.

convalescent sera adsorbed with PRP and PPS $_{\text {Eag }}$ (Table IV). Reagents prepared from the convalescent sera of Tur (after both infections) failed to kill either Tur isolate at titers useful for analysis $(>4)$. The reagent from the first convalescent serum of Sil was similarly inactive, but she responded to the second infection with antibodies that (after the adsorptions) killed her second isolate at a higher titer than her first isolate (titers 16 and 4, respectively). Thus in both patients the second infecting strain differed discernibly from the first in expression of somatic antigens.

TABLE III

Susceptibility to Anti-LPS ${ }_{\text {Eag }}$ of H.i.b Prepared without and with HSD

\begin{tabular}{|c|c|c|c|}
\hline \multirow[b]{2}{*}{ Strain } & \multirow{2}{*}{$\begin{array}{l}\text { Antigen } \\
\text { makeup } \\
\text { of strain }\end{array}$} & \multicolumn{2}{|c|}{$\begin{array}{c}\text { BC titer of rabbit R217 } \\
\text { anti-LPS } \\
\text { bacteria prepared }\end{array}$} \\
\hline & & -HSD & $+\mathrm{HSD}$ \\
\hline C58 & 1 & 320 & $<40$ \\
\hline H 123 & 2 & $>320$ & $<40$ \\
\hline Rab & 1,2 & 160 & $<40$ \\
\hline H234 & $1,2,3$ & $>1,280$ & 320 \\
\hline 6510 & 1,4 & $>1,280$ & $<40$ \\
\hline H305 & 5 & $<40$ & $<40$ \\
\hline Mad & 5,6 & $<40$ & $<40$ \\
\hline
\end{tabular}

\section{DISCUSSION}

A rapid phenotypic alteration in susceptibility to $\mathrm{BC}$ antisomatic antibody was originally described for one strain of H.i.b in response to components low in molecular weight of the serum of one animal species, the rat (14). A similar effect was recently reported for another strain exposed to whole, heat-inactivated normal rat serum (13), although components high in molecular weight such as blocking antibody, were not ruled out as effectors. The present finding that incubation with the dialysate of human serum (three of three tested) induces a shift suggests that normal component(s) of mammalian serum are responsible and that the phenomenon is relevant to the analysis of human immunity. A shift was seen in all but three of the H.i.b isolates tested (and might have been demonstrable in these if antisera to their LPS had been available); thus it appears to be a general property of H.i.b. The shift is in resistance to antibodies directed against determinant(s) in LPS rather than against somatic antigens in general. The restricted specificity suggests that the alteration operates at the level of antibody binding rather than at subsequent stages of complement-mediated bacteriolysis. Moreover, although only bacteriolysis has been examined, it seems possible that antibody-mediated opsonization or other antibody-mediated immune mechanisms would likewise be affected by the shift.

The component(s) of serum causing the shift and the 
TABLE IV

Analysis of H.i.b Isolates from Recurrent Systemic Infection by Means of Antisomatic BC Antibodies

\begin{tabular}{|c|c|c|c|c|c|}
\hline \multirow[b]{2}{*}{ Isolate } & \multirow{2}{*}{$\begin{array}{l}\text { Site and date } \\
\text { of isolation }\end{array}$} & \multirow{2}{*}{$\begin{array}{l}\text { Antigen } \\
\text { makeup }\end{array}$} & \multirow{2}{*}{$\begin{array}{l}\text { Susceptibility } \\
\text { to rabbit R217 } \\
\text { anti-LPS } \\
\text { Eas }\end{array}$} & \multicolumn{2}{|c|}{$\begin{array}{l}\text { Susceptibility to patient's } \\
\text { serum adsorbed with } \\
\text { PRP and LPS } \\
\text { Eas* }\end{array}$} \\
\hline & & & & Post 1f & Post $2 \S$ \\
\hline Tur 1 & CSF," 1-2-71 & - & $<40$ & $<4$ & $<4$ \\
\hline Tur 2 & CSF, 7-2-71 & 1 & $>320$ & $<4$ & $<4$ \\
\hline Sil 1 & CSF, 9-8-71 & 1 & 160 & $<4$ & 4 \\
\hline Sil 2 & NP, $10-19-71$ & 1 & 160 & $<4$ & 16 \\
\hline
\end{tabular}

* BC titer against bacteria prepared without incubation with human serum dialysate.

\$ Serum sample taken 1-9 wk after onset of the patient's first infection; treated with penicillinase before assay.

$\S$ Taken after second infection, etc.

"Cerebrospinal fluid.

If Nasopharynx. (The illness was sepsis without meningitis; however, the isolate from blood was lost.)

structural basis of the altered antigenicity have not yet been identified. An impediment has been that dialysate is able to shift the bacteria only at a low density ( $\leqslant$ ca. $10^{7} \mathrm{CFU} / \mathrm{ml}$ ), and generation of the large population of resistant organisms necessary for isolation and analysis of LPS would be impractical.

For most questions concerning immunity it is of course preferable to examine bacteria as they exist in vivo. Use of bacteria harvested from infected hosts, however, would be impractical for many types of experiments. In respect to $\mathrm{BC}$ antibody susceptibility, brothgrown H.i.b briefly exposed to rat serum dialysate resembled H.i.b recovered from the circulation of infected rats (14). It should not be concluded that the incubation with dialysate confers a phenotype equal in every respect to that in vivo, but the dialysate apparently generates a closer approximation. The bacteria prepared without and with dialysate were identical in susceptibility to antiserum reagents specific for antigens 2-6 and differed only in expression of factor 1 (plus an undefined factor present in $\mathrm{LPS}_{\text {Eag }}$ and in strain H123). Factor 1, however, was the most broadly distributed of the factors identified. Use of conventionally prepared bacteria for determination of serum bactericidal activities thus tends to inflate the apparent titers, particularly in sera low in anticapsular antibodies (such as sera of human infants). Even H.i.b grown in media with a high content of animal blood, e.g., Levinthal medium (2), might be hyper-susceptible, because when brain heart infusion broth was present during exposure to dialysate the phenotypic shift was antagonized (14). Thus surveys correlating immune status with serum bactericidal or opsonic activity against an index organism may be subject to misinterpretation as a result of phenotypic varia- tion within a strain and genetic differences among strains.

There is considerable genetic variation in the expression of antibody-accessible antigens of H.i.b: among the 13 strains initially analyzed, seven different patterns of susceptibility to cross-adsorbed antisera were found. The results could be accounted for by the variable expression of as few as six antigens. Use of antiserum to LPS $_{\text {Eag }}$ suggested an additional determinant present in LPS $_{\text {Eag }}$ and expressed in strain H123 but distinct from antigen 1. Examination of four additional isolates (from recurrent infections) revealed yet another differentially expressed antigen.

Some BC activity of the cross-adsorbed antisera conceivably could be the result of variant determinants in capsular polysaccharide; however, no such variation has been reported. PRP from strains Eag, Rab, H305, and Mad were alike in composition (24), and the two former were found to be structurally identical $(25,26)$. Because four of the reagent antisera were raised against these strains, at least four of the variable antigens appear to be somatic rather than capsular.

Antigen 1 resides in LPS, as does the unclassified antigen in strain H123. The structural category of the other variable antigens is presently unknown. When compared by indirect hemagglutination with LPS $_{\text {Eag, }}$, LPS from strain H305 displayed both shared and notshared determinants (18; N.B., the LPS preparations were designated $b$ and $b^{\prime}$, respectively). Thus antigen 5 may also be contained in LPS. Strain Eag is quite susceptible to somatic antibodies not adsorbed by LPS $_{\text {Eag }}$ (Table I), so the corresponding determinants either are not a part of LPS or are not conserved when LPS is purified (18) by the phenol-water method. The possible relation of non-LPS-adsorbed somatic BC anti- 
bodies and the outer membrane proteins of H.i.b is currently under study.

In the patients with recurrent systemic infections the second isolates were shown to differ from the first in antigens expressed. This observation is more consistent with the second illnesses being due to newly acquired strains of H.i.b rather than to recrudescence of sequestered organisms from the first infections. Two of these strains will be of particular interest in further study of the distribution and surface exposure of somatic antigens of H.i.b: strain Tur 1 expressed no somatic antigens susceptible to the six reagent antisera or to antibodies elicited in the patient. It will be of interest to determine whether it exposes somatic antigens not apparent in this study or exposes none. Strains Sil 1 and 2 were identical in respect to the antigens 1-6, but Sil 2 was more susceptible to an antibody elicited in the patient. Thus Sil 2 and Tur 1 (along with $\mathrm{H} 123$ ) would be useful for extending the subtyping system.

Somatic antigens may be pertinent to vaccination against $\mathbf{H}$.i.b. The human antibody response to vaccination with purified PRP is age dependent $(27,8)$. PRP vaccine appeared to be protective only after age $18 \mathrm{mo}$ (3), whereas the maximal incidence of H.i.b meningitis occurs in the first year of life. Antibody-accessible somatic antigens to which immunocompetence matured early in human development would be useful to identify, particularly such an antigen homogeneously distributed among H.i.b strains. The cross-adsorbed antisera used here would lack antibody to a universal somatic antigen but would be useful in discerning it from the variably expressed antigens. In addition, $H$. influenzae otitis media is primarily the result of unencapsulated strains, and their somatic antigens might reasonably be examined for immunoprotective potential. Thus an antigen common to H.i.b and H.i. causing otitis would be ideal. Further biochemical and immunological studies will be required to determine whether such an antigen exists.

\section{ACKNOWLEDGMENTS}

The authors are grateful to Hei Sun Lee and Joyce Colaiace for technical assistance, to Doctors V. M. Howie, David Ingram, and Georges Peter for bacterial strains and human sera, and to Marilyn Loeb and Richard Insel for a critique of the manuscript.

This work was supported by U. S. Public Health Service grant AI 71-2196.

\section{REFERENCES}

1. Wright, J., and H. K. Ward. 1932. Studies on influenzal meningitis: II. The problem of virulence and resistance. J. Exp. Med. 55: 235-246.

2. Alexander, H. E. 1958. Hemophilus influenzae. In Bacterial and Mycotic Infections of Man. R. J. Dubos, editor. J. B. Lippincott Company, Philadelphia. 470-485.
3. Makela, P. H., H. Peltola, H. Kayhty, H. Jousimies, O. Pettay, E. Ruoslahti, A. Sivonen, and O. V. Renkonen. 1977. Polysaccharide vaccines of Group A Neisseria meningitidis and Haemophilus influenzae type b: a field trial in Finland. J. Infect. Dis. 136: S43-S50.

4. Fothergill, L. D., and J. Wright. 1933. Influenzal meningitis. The relation of age incidence to the bactericidal power of blood against the causal organism. J. Immunol. 24: 273-284.

5. Feigin, R. D., D. Richmond, M. W. Hosler, and P. G. Shackelford. 1971. Reassessment of the role of bactericidal antibody in Hemophilus influenzae infection. Am. J. Med. Sci. 262: 338-346.

6. Mpairwe, Y. 1971. Immunity to Haemophilus influenzae type b: the rose of capsular antibody. J. Med. Microbiol. 4: $85-88$.

7. Anderson, P., R. B. Johnston, Jr., and D. H. Smith. 1972. Human serum activities against Hemophilus influenzae, type b. J. Clin. Invest. 51: 31-38.

8. Smith, D. H., G. Peter, D. L. Ingram, A. L. Harding, and P. Anderson. 1973. Responses of children immunized with the capsular polysaccharide of Hemophilus influenzae, type b. Pediatrics. 52: 637-644.

9. Norden, C. W., and H. A. Feldman. 1975. Hemophilus influenzae type $\mathrm{b}$ antibody frequencies determined with bactericidal and radioimmunoassay tests. J. Clin. Microbiol. 2: 136-138.

10. Norden, C. W. 1972. Variable susceptibility of Hemophilus influenzae, type $\mathrm{b}$ strains to serum bactericidal activity. Proc. Soc. Exp. Biol. Med. 139: 59-61.

11. Weller, P. F., A. L. Smith, D. H. Smith, and P. Anderson. 1976. The role of immunity in the clearance of Haemophilus influenzae bacteremia. J. Infect. Dis. 138: 427-438.

12. Myerowitz, R. L., and C. W. Norden. 1977. Immunology of the infant rat experimental model of Haemophilus influenzae type b meningitis. Infect. Immun. 16: 218-225.

13. Granoff, D. M., and R. Rockwell. 1978. Experimental Haemophilus influenzae type b meningitis: immunological investigation of the infant rat model. Infect. Immun. 20: 705-713.

14. Shaw, S. A., A. L. Smith, P. Anderson, and D. H. Smith. 1976. The paradox of Hemophilus influenzae type b bacteremia in the presence of serum bactericidal activity. J. Clin. Invest. 58: 1019-1029.

15. Zoon, K. C., and J. J. Scocca. 1975. Constitution of the cell envelope of Haemophilus influenzae in relation to competence for genetic transformation. J. Bacteriol. 123: 666-677.

16. Branefors-Helander, P. 1973. Serological studies of Haemophilus influenzae: III. The endotoxic effect of various antigen preparations and the relation between this effect and demonstrable precipitinogens. Int. Arch. Allergy Appl. Immunol. 44: 585-600.

17. Branefors-Helander, P. 1973. Serological studies of Haemophilus influenzae: IV. The antibody response in rabbits against capsular and $\mathrm{O}$ antigens of $H$. influenzae. Int. Arch. Allergy Appl. Immunol. 45: 657-674.

18. Flesher, A. R., and R. A. Insel. 1978. Characterization of lipopolysaccharide of Haemophilus influenzae. J. Infect. Dis. 138: 719-730.

19. Kilian, M. 1976. Taxonomic study of the genus Haemophilus. J. Gen. Microbiol. 93: 9-62.

20. Gold, R., and F. A. Wyle. 1970. New classification of Neisseria meningitidis by means of bactericidal reactions. Infect. Immunol. 1: 479-487.

21. Anderson, P., and D. H. Smith. 1977. Isolation of the capsular polysaccharide from culture supernatant of 
Haemophilus influenzae type b. Infect. Immunol. 15: 472-477.

22. Anderson, P. 1978. Intrinsic tritium labeling of the capsular polysaccharide antigen of Haemophilus influenzae type b. J. Immunol. 120: 866-870.

23. Engvall, E., and P. Perlmann. 1972. Quantitation of specific antibodies by enzyme-linked anti-immunoglobulin in antigen-coated tubes. J. Immunol. 109: 129-135.

24. Anderson, P., J. Pitt, and D. H. Smith. 1976. The synthesis and release of polyribophosphate by Haemophilus influenzae type b in vitro. Infect. Immunol. 13: 581-589.
25. Crisel, R. M., R. S. Baker, and D. E. Dorman. 1975. Capsular polymer of Haemophilus influenzae, type b. J. Biol. Chem. 250: 4926-4934.

26. Branefors-Helander, P., C. Erbing, L. Kenne, and B. Lindberg. 1976. Structural studies of the capsular antigen from Haemophilus influenzae type b. Acta Chem. Scand. Ser. B. Org. Chem. Biochem. 30: 276-277.

27. Robbins, J. B., J. C. Parke, Jr., R. Schneerson, and J. K. Whisnant. 1973. Quantitative measurement of "natural" and immunization-induced Haemophilus influenzae type b capsular polysaccharide antibodies. Pediatr. Res. 7: 103-110. 